\title{
Identification of Safe Assembly Points in Emergencies in a Gas Refinery of the South Pars Gas Complex Using Fuzzy Logic Model
}

\author{
Salehe Nematifard ${ }^{1} \mathbb{D}$, Katayoun Jahangiri ${ }^{2} \mathbb{D}$, Alireza Haj Qasem Khan $^{3}(\mathbb{D}$, Hamid Reza Jamshidi \\ Solukloei $^{4} \oplus$, Saeed Bahramzadeh Gandeshmin ${ }^{1} \mathbb{D}, \underline{\text { Ghazaleh Monazami Tehrani }} \mathbf{1}^{*^{*}} \mathbb{C}$
}

Date of submission: 13 Jun. $2018 \quad$ Date of acceptance: 27 May. 2020

\section{Original Article}

\begin{abstract}
INTRODUCTION: Crisis management is of critical importance in the oil and gas industries due to the increasing occurrence of accidents in these areas. One of the most important issues regarding crisis management in such industries is the identification of safety assembly points where employees should gather in emergencies. This study aimed to identify the safe points in a refinery using geographic information system (GIS) and fuzzy logic for emergency assembly.

METHODS: Regarding the aim of the study purpose, the required data were collected, and a focus group meeting was held with experts to determine the criteria influencing the safety point zoning as well as high-risk units using the HAZOP method. After the identification of the criteria and sub-criteria affecting the zoning, the weight of each zoning parameter was calculated, and the safety zones were determined using the fuzzy logic model and its operators in the GIS environment.

FINDINGS: According to the results of the risk assessment, the criteria and sub-criteria affecting zoning were divided into three categories of inconsistent (layer weight: 0.740), consistent (layer weight: 0.094), and access to exit routes (layer weight: 0.167). Moreover, the map results based on the fuzzy logic model revealed three safe points, including the vicinity of the fire station, clinic, and wastewater treatment plant in this refinery where the employees should gather in the event of emergencies.

CONCLUSION: The results of this study showed that the selection of appropriate criteria in safe point zoning is of great importance in the emergencies in the industries. Moreover, an initial risk assessment can be effective in determining these criteria and sub-criteria. In addition, the fuzzy logic model has high accuracy and precision in determining the appropriate safe places.
\end{abstract}

Keywords: Emergencies; Fuzzy Logic Model; Gas Refinery; Safe Point Zoning.

How to cite this article: Nematifard S, Jahangiri K, Haj Qasem Khan A, Jamshidi Solukloei HR, Bahramzadeh Gandeshmin S, Monazami Tehrani G. Identification of Safe Assembly Points in Emergencies in a Gas Refinery of the South Pars Gas Complex Using Fuzzy Logic Model. Sci J Rescue Relief 2019; 11(4): 275-86.

\section{Introduction}

$\mathrm{T}$ he severity of adverse consequences is high in crises; therefore, the emergency response team such as the main control team (MCT) and forward control team (FCT) cannot deal with it alone. Accordingly, when deciding on an unfortunate event, (whether it is a crisis or just an accident), the ability of the emergency response team to deal with it should be measured. Crisis in the industry is an

\footnotetext{
1-Department of Health, Safety and Environment, School of Public Health and Safety, Shahid Beheshti University of Medical Sciences, Tehran, Iran

2-Department of Health in Disasters and Emergencies, School of Public Health and Safety, Shahid Beheshti University of Medical Sciences, Tehran, Iran

3-Department of Occupational Health, School of Public Health and Safety, Shahid Beheshti University of Medical Sciences, Tehran, Iran 4-Department of Occupational Health, School of Health, Tehran University of Medical Sciences, Tehran, Iran

Correspondence to: Ghazaleh Monazami Tehrani, Email: ghazaleh.monazami@sbmu.ac.ir
} 
unexpected event leading to disruptions in production, thereby resulting in far-reaching financial, human, or environmental impacts on the area and the environment (1-3).

Nowadays, special industry zones with a high density of operational units are one of the main sources of industrial crises around the world. Mahshahr Petrochemical Special Economic Zone (PETZONE) and Pars Special Economic Energy Zone (PSEEZ) have such features in Iran. The high volume of materials, process temperature and pressure conditions, and the proximity of process equipment to each other have made these areas potential points for the occurrence of major accidents and crises (4-6).

The accidents that occurred in industrial units can have much more severe consequences due to the very high volume of materials and substances. The major events or crises in the industries are of great importance from different perspectives. Firstly, due to the high volume of materials, some of which are flammable hydrocarbons or highly toxic substances. Therefore, the number of deaths and casualties can be very high in industrial units in case of the occurrence of accidents.

Secondly, each of these industrial units, as part of a large production chain, consumes the products or fulfills the feed of another unit. Therefore, accidents in such units lead to the disruption of the production cycle and many financial losses. Although efforts have been made to improve the safety of industrial units, major accidents or industrial crises still occur in these units.

As a result, the improvement of safety degree using enhanced control equipment and design optimization does not necessarily guarantee the elimination of accidents. Therefore, there have been interests in the utilization of management approaches as a complement to safety to deal with accidents and crises in the industry. To this end, risk and crisis management plans have been presented and implemented in the industry (7-10).

Industries determine how to react to emergencies at the accident scene. Some organizations protect their employees in emergencies using appropriate prevention plans and evacuation the employees from danger to safe points. Moreover, they account for public emergency services organizations to deal with the accidents at the community level.

The majority of the industries try to take the responsibility of emergency response measures until the external emergency responders arrive at the scene of an incident, thereby reducing the severity of injuries $(1,9,11)$.

Reaction to disasters and other emergencies is not only a requirement but also it leads to reducing the amount of damage to the organization. Some of the requirements and regulations in this situation include emergency evacuation, the presence of firefighters, and emergency response teams in an enclosed area, as well as the medical team. In general, these regulations include training along with the preparation and utilization of equipment accompanied by other issues affecting the performance of personnel (12-14) .

According to the literature, the identification of safe points for assembling the employees during emergencies is one of the most important ways to gather staff, ensure their health, and evacuate them from the accident scene. To this end, classical mathematical methods have been used to determine the safe points at work $(3,15)$. The researchers in classical mathematics have selected safety places without considering industry conditions and eliminating uncertainties.

Safety and health experts make mistakes in planning the safety points because they do not consider hidden factors and the problems related to determining evacuation assembly areas using classical mathematics in the industries $(8,10)$. Therefore, there is a need for a method to examine the hidden root causes and eliminates uncertainties.

In addition, the results of several studies to identify safe points in cities, hospitals, and industrials demonstrated that fuzzy set theory can provide more accurate results in terms of the identification of safe assembly areas in emergencies $(3,16)$.

Crisis management is of significant importance in Iran, due to the presence of oil and gas industries. Refineries are one of the most important parts of this industry. The safety enhancement should be considered in refineries since any hazard in this industry leads to environmental and human irreversible damage in addition to economic challenges $(17,18)$.

Therefore, this study aimed to use fuzzy logic modeling to identify the safe assembly points where employees should gather in the event of emergencies in a gas refinery in Iran. 


\section{Scopes of the study}

Scopes of this study were selected based on the importance of risks in gas refineries, location of the refinery being one of the high-risk industries in the PSEEZ, possibility of crisis in PSEEZ when refineries are $\mathrm{v}$, and fencing as well as traffic restrictions using security gates and guardians.

\section{Methods}

The following steps represented the identification of safe points for staff to assemble in the event of emergencies. Initially, risk assessment was performed using the HAZOP method for all units of the refinery. Moreover, to define the scenario (toxic material release, as well as fire and explosion, flammable, and explosive chemical substances) based on HAZOP results in this study, it was assumed that all control valves operated automatically and any deviation was also investigated in this study. In addition, due to the avoidance of repetition, opening of the bypass route of the control valves was not regarded as a factor for operational disturbances, such as increased flow.

The control system monitors the situation by closing the valve; however, there is a low probability that this will happen. Chemical process emergencies rarely occur as a result of one factor, and in most cases, predisposing causes and intermediate events, including safety measures and human interventions, are involved.

It has generally been found that it is impossible to identify all probable causes, moderator effects, and final consequences of potential scenarios. Therefore, if all factors are considered in complex process equipment, there will be a great number of potential scenarios about fires, explosions, as well as the material release of toxic and flammable substances. As a result, it is inevitable to eliminate some of them in emergency planning. Accordingly, scenarios that are more potential to occur are considered in process risk analysis $(3,4)$.

Regarding emergency planning, a great deal of attention should be paid to several factors in an industry. Therefore, all industries have to identify valid events in this regard. The expert group in this study included expert or managers; heads of exploitation units (refining, utility, and sulfur recovery), process engineering, and HSE (safety and firefighting); a risk assessment expert, and an occupational health expert, (number of team members $=12$ ) who participated in conducting the study.

In the next stage, the expert team determined the effective parameters according to the results of the studies conducted in Iran and other countries to identify the appropriate criteria for safe point zoning as well as influencing factors, such as human factors, high-risk equipment, personnel accommodation, traffic areas, fences, and security gates).

Following that, descriptive and spatial information (AutoCAD maps) was received from the engineering unit to locate safe points.

Next, the collected data were prepared for spatial analysis operations in the geographical information system (GIS) software. Therefore, all information layers were converted into shapefiles and mapped on a scale of 1:1,500. Furthermore, the projection was performed to define the coordinate system.

According to the geographical location of the study area, the coordinate system of each data was converted to the UTM1-39 system and WGS1984 basis in the GIS environment followed by cutting out operation 3. Moreover, the information layer cutting out process was performed based on the area under study $(8,19)$. To raster the layers, the spacing was set to 1 in several layers $(20,21)$, which led to 10 layers in this study. Finally, the results were useful for the identification of safe assembly areas. In the next step, the criteria and sub-criteria (affective factors) weights were calculated to determine the importance and value of each factor, compared to other factors, using the AHP method. To this end, a focused group discussion method (using a group of experts) was used in this study. The guidelines and contents of the focus group discussion were prepared in advance and distributed among the experts before the meeting.

Binary comparisons were used to prepare the guidelines. Following that, the final matrix was completed based on the scores given by the experts. The clock drawing test scoring system was used to score the items from 9 to 1.9. Subsequently, the maps of each layer were prepared after identifying and preparing all the criteria and effective factors in locating safe points and weighting the criteria and sub-criteria (components).

In the final step, the layers overlapped with 
each other using the Raster Calculator in GIS. In the next step, subsequently, each of the general criteria was multiplied by their weight again and they were overlaid after weight calculation.

Finally, the layers were combined using the fuzzy logic model, and the fuzzy layers obtained from the preparation layer step were extracted using the Fuzzy Membership function in GIS. Layers were identified one by one, and low (it is better if the staff assembly is closer to the component), as well as high (it is better if the staff assembly is further away from the component) items, were identified for the layers. The fuzzy maps were then overlapped with each other and combined; moreover, 5 fuzzy operators in the GIS were investigated in this study using gamma 0.1 0.9 functions on 10 maps $(3,8,10)$. The fuzzy operators were fuzzy OR, fuzzy AND, fuzzy algebraic product, fuzzy algebraic sum, and fuzzy gamma.

The rules of fuzzy logic or its operators are as follows:

\section{A) Fuzzy $\mathrm{OR}$}

This operator uses the minimum function in the overlap and is equivalent to subscription. It is defined using $E q(1)$ :

$\mu_{\text {combination }}=\operatorname{MIN}\left\{\mu_{A}, \mu_{B}, \mu_{C}, \ldots\right\} \quad E q 1$.

Where $\boldsymbol{\mu c o m b i n a t i o n}$ is the calculated fuzzy membership function, $\boldsymbol{\mu} \boldsymbol{A}$ signifies the membership value for map $\mathrm{A}$, and $\boldsymbol{\mu} \boldsymbol{B}$ indicates the value for map B.

This operator is used for independent parameters or when there should be two or more evidence to prove a hypothesis.

\section{B) Fuzzy AND}

This operator utilizes the maximum function in combination and is defined using $E q(2)$ :

$\mu_{\text {combination }}=\operatorname{MAX}\left\{\mu_{A}, \mu_{B}, \mu_{C}, \ldots\right\} \quad E q 2$.

Out of two membership functions, this operator selects the function with the maximum amount of function.

\section{C) Fuzzy algebraic product operator}

The membership function in this operator is defined using Eq (3) as follows: $\mu_{\text {combination }}=1-\prod_{i=0}^{n}\left(1-\mu_{i}\right)$

Eq3.

Where $\boldsymbol{\mu}_{\mathrm{i}}$ is the fuzzy membership function for the $\mathrm{i}$-th map, and $\mathrm{i}=1,2, \ldots, \mathrm{n}$ signifies the number of the maps that are to be combined

The amount of fuzzy membership that is combined using this operator becomes smaller due to the multiplication of some numbers smaller than 1.

\section{D) Fuzzy algebraic sum operator}

The fuzzy membership function of this operator is obtained using Eq (4).

$\mu_{\text {combination }}=1-\prod_{i=1}^{n}\left(1-\mu_{i}\right)$

Eq4.

\section{C) Fuzzy gamma operator}

The gamma operation is defined in terms of the fuzzy algebraic product and the fuzzy algebraic sum using $E q(5)$ :

$\mu_{\text {combination }}=(\text { FuzzyAlg.Sum })^{y} \times$ (FuzzyAlg.Product) $)^{1-y}$

Eq5.

Where $\mathrm{y}$ is a parameter selected within the range of $(0,1)$

The determined parameter is between 0 and 1 . The gammas equal to 0 and 1 are equivalent to fuzzy product and sum operators, respectively. Appropriate selection of the parameter leads to the extraction of values in the output which are consistent with an increase in the algebraic sum and a decrease in the algebraic product.

\section{Findings}

This section presents the research finding, risk assessment results, identification of the effective criteria in zoning, determination of the degree of importance and criteria weighting in zoning, and output of the two models using information layer combination in maps.

Based on the results of the HAZOP risk assessment, high-risk units have effects on the identification of the safe assembly areas where employees should gather in the event of emergencies (Table 1).

The other important factors identified by experts included the presence of a fire station, clinic, green space, and access to exit doors and routes. 
Table 1. Criteria influencing the identification of the safe assembly areas where employees should gather in the event of emergencies based on the results of risk assessment

$1 \quad$ Sulfur recycling unit

Gas sweetening unit

Gas and gas condensate receiving and separation unit

Sulfur granulation unit
Demercaptanization unit

Gas dehumidification unit

Gas condensate stabilization unit

Dew point adjustment unit

Gas station

Condensate storage unit

Gas system unit with high and low pressure towards the flare

Condensate pumps unit

Burn Pit Unit (Waste Incinerator)

Sour Water Unit
The high-risk unit was identified by a specialized committee in the risk assessment process using the HAZOP method

The high-risk unit was identified by a specialized committee in the risk assessment process using the HAZOP method

The high-risk unit was identified by a specialized committee in the risk assessment process using the HAZOP method

The high-risk unit was identified by a specialized committee in the risk assessment process using the HAZOP method

The high-risk unit was identified by a specialized committee in the risk assessment process using the HAZOP method

The high-risk unit was identified by a specialized committee in the risk assessment process using the HAZOP method

The high-risk unit was identified by a specialized committee in the risk assessment process using the HAZOP method

The high-risk unit was identified by a specialized committee in the risk assessment process using the HAZOP method

The high-risk unit was identified in the risk assessment process using the HAZOP method

The high-risk unit was identified by a specialized committee in the risk assessment process using the HAZOP method

The high-risk unit was identified by a specialized committee in the risk assessment process using the HAZOP method

The high-risk unit was identified in the risk assessment process using the HAZOP method

The high-risk unit was identified by a specialized committee in the risk assessment process using the HAZOP method

The high-risk unit was identified by a specialized committee in the risk assessment process using the HAZOP method

The high-risk unit was identified by a specialized committee in the risk assessment process using the HAZOP method

The high-risk unit was identified by a specialized committee in the risk assessment process using the HAZOP method
Meeting with a specialized committee

Meeting with a specialized committee

Meeting with a specialized committee

Meeting with a specialized committee

Meeting with a specialized committee

Meeting with a specialized committee

Meeting with a specialized committee

Meeting with a specialized committee

Meeting with a specialized committee

Meeting with a specialized committee

Meeting with a specialized committee

Meeting with a specialized committee

Meeting with a specialized committee

Meeting with a specialized committee

Meeting with a specialized committee

Meeting with a specialized committee 


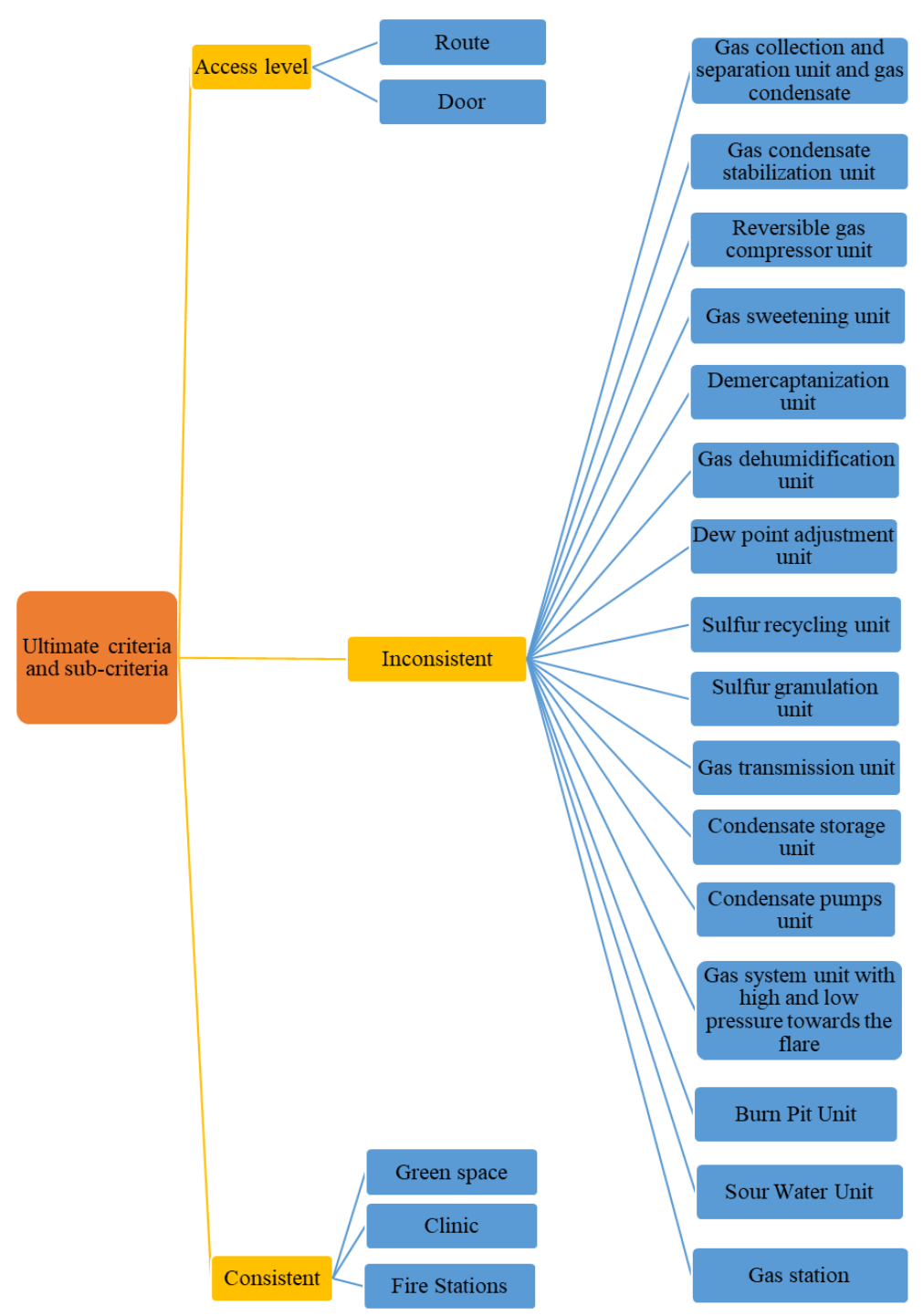

Figure 1. Criteria to determine the safe assembly areas in the refinery

Figure 1 shows the results of expert group meetings and risk assessments regarding criteria and sub-criteria affecting safe point zoning.

Table 2 tabulates the results of the binary comparison of factors.

The results of a binary comparison of access levels are presented in Table 3.

Table 4 tabulates the binary comparison matrix of inconsistent criteria involving high-risk units.

Table 2. Binary comparison matrix of consistent

\begin{tabular}{|c|c|c|c|}
\hline Criteria & (A) & (B) & (C) \\
\hline Fire station (A) & 1 & 5 & 3 \\
\hline Clinic(B) & 0.2 & 1 & 0.5 \\
\hline $\begin{array}{l}\text { Space area }(C) \\
\text { consistency rate }\end{array}$ & 0.33 & $\begin{array}{c}2 \\
00.00\end{array}$ & 1 \\
\hline
\end{tabular}

The general criteria based on consistent and inconsistent factors, as well as access levels are presented in Table 5 .

Table 6 summarizes the ultimate criteria and sub-criteria weights affecting safe point zoning. The weights are divided into three categories of consistent and inconsistent, as well as access levels.

Figure 2 illustrates the location and coordination of different units of the refinery, including, sulfur recycling and granulation units,

Table 3. Binary comparison matrix of the access level

\begin{tabular}{cccc} 
Criteria & (A) & (B) \\
Door (A) & 1 & 0.33 \\
Route (B) & 3 & & 1 \\
consistency rate & & 00.00 & \\
\hline
\end{tabular}


Table 4. Binary comparison matrix of inconsistent criteria

\begin{tabular}{|c|c|c|c|c|c|c|c|c|c|c|c|c|c|c|c|c|}
\hline Criteria & (A) & (B) & (C) & (D) & (E) & (F) & (G) & (H) & (I) & (J) & (K) & (L) & (M) & (N) & (0) & (P) \\
\hline Sulfur recycling unit (A) & 1 & 1 & 2 & 2 & 3 & 4 & 5 & 5 & 6 & 6 & 7 & 8 & 8 & 8 & 9 & 9 \\
\hline Gas sweetening unit (B) & 1 & 1 & 2 & 2 & 3 & 4 & 5 & 5 & 6 & 6 & 7 & 8 & 8 & 8 & 9 & 9 \\
\hline Gas delivery unit (C) & 50.0 & 50.0 & 1 & 1 & 2 & 3 & 4 & 4 & 5 & 5 & 6 & 7 & 7 & 7 & 8 & 8 \\
\hline $\begin{array}{l}\text { Gas and gas condensate receiving and } \\
\text { separation unit (D) }\end{array}$ & 50.0 & 50.0 & 1 & 1 & 2 & 3 & 4 & 4 & 5 & 5 & 6 & 7 & 7 & 7 & 8 & 8 \\
\hline Reversible gas compressor unit (E) & 33.0 & 33.0 & 5.0 & 25.0 & 1 & 2 & 3 & 3 & 4 & 4 & 5 & 6 & 6 & 6 & 7 & 7 \\
\hline Sulfur granulation unit $(\mathrm{F})$ & 25.0 & 25.0 & 33.0 & 33.0 & 5.0 & 1 & 2 & 2 & 3 & 3 & 4 & 5 & 5 & 5 & 6 & 6 \\
\hline Demercaptanization unit (G) & 20.0 & 20.0 & 25.0 & 25.0 & 33.0 & 5.0 & 1 & 1 & 2 & 2 & 3 & 4 & 4 & 4 & 5 & 5 \\
\hline Gas dehumidification unit $(\mathrm{H})$ & 20.0 & 20.0 & 25.0 & 25.0 & 33.0 & 5.0 & 1 & 1 & 2 & 2 & 3 & 4 & 4 & 4 & 5 & 5 \\
\hline Gas condensate stabilization unit (I) & 17.0 & 17.0 & 20.0 & 20.0 & 25.0 & 1 & 50.0 & 50.0 & 1 & 1 & 2 & 3 & 3 & 3 & 4 & 4 \\
\hline Dew point adjustment unit $(\mathrm{J})$ & 17.0 & 17.0 & 20.0 & 20.0 & 33.0 & 33.0 & 50.0 & 50.0 & 1 & 1 & 2 & 3 & 3 & 3 & 4 & 4 \\
\hline Gas station $(\mathrm{K})$ & 14.0 & 14.0 & 17.0 & ro. & 20.0 & 25.0 & 33.0 & 33.0 & 50.0 & 50.0 & 1 & 2 & 2 & 2 & 3 & 3 \\
\hline Condensate storage unit (L) & 13.0 & 13.0 & 14.0 & 14.0 & 17.0 & 20.0 & 25.0 & 25.0 & 33.0 & 33.0 & 50.0 & 1 & 1 & 1 & 2 & 2 \\
\hline $\begin{array}{l}\text { Gas system unit with high and low } \\
\text { pressure towards the flare (M) }\end{array}$ & 13.0 & 13.0 & 14.0 & 14.0 & 17.0 & 20.0 & 25.0 & 25.0 & 33.0 & 33.0 & 50.0 & 1 & 1 & 1 & 2 & 2 \\
\hline Condensate pumps unit $(\mathrm{N})$ & 13.0 & 13.0 & 14.0 & 14.0 & 17.0 & 20.0 & 25.0 & 17.0 & 33.0 & 33.0 & 50.0 & 1 & 1 & 1 & 1 & 1 \\
\hline Burn pit unit (waste incinerator) (o) & 11.0 & 11.0 & 13.0 & 13.0 & 14.0 & 17.0 & 20.0 & 20.0 & 25.0 & 25.0 & 33.0 & 50.0 & 50.0 & 1 & 1 & 1 \\
\hline Sour water unit $(\mathrm{P})$ & 11.0 & 11.0 & 13.0 & 13.0 & 14.0 & 17.0 & 20.0 & 20.0 & 25.0 & 25.0 & 33.0 & 50.0 & 50.0 & 1 & 1 & 1 \\
\hline Inconsistency rate & \multicolumn{16}{|c|}{00.00} \\
\hline
\end{tabular}

Table 5. General criteria

\begin{tabular}{cccc} 
Criteria & (A) & (B) & (C) \\
Consistent (A) & 1 & 14.0 & 5.0 \\
Inconsistent (B) & 7 & 1 & 5 \\
Access level (C) & 2 & 2.0 & 1 \\
Inconsistency rate & & 00.00 & \\
\hline
\end{tabular}

gas dehumidification, gas delivery, burn pit and flare, condensate and dew point pumps, condensate storage recyclers, gas condensate stabilization, reversible gas compressors, gas sweetening, receiving and separation gas and gas condensate, Demercaptanization, sour water, and gas system with high and low pressure towards the flare.

Additionally, fuzzy layers of the effective factors are presented in Table 7.

The numbers in table 7 signify the following data:

Number 1: Membership degree 1 belongs to the fire station that obtained the highest level of safety rating. The safety rating decreases when the distances increase (minimum membership rating is equal to 0.3 ) .

Number 2: Membership grade 0.0058 belongs to the gas station that obtained the highest level of risk score and lowest membership grade (0.666), which reduces the risk level.

Number 3: Membership grade 0.0075 is related to the sour-water unit that obtained the highest level of risk and lowest membership grade (0.666), which reduces the risk level.

Number 4: Membership grade 0.0065 is related to the sulfur-recycling unit that obtained the highest level of risk and lowest membership grade (0.666), which reduces the risk level.
Number 5: Membership grade 0.0077 is related to the burn pit and flare gas units that obtained the highest level of risk and lowest membership grade $(0.666)$, which reduces the risk level.

Number 6: Membership grade 0.0087 is related to the gas condensate stabilization unit that obtained the highest level of risk and lowest membership grade $(0.667)$, which reduces the risk level.

Number 7: Membership grade 0.0075 is related to the dew point adjustment unit that obtained the highest level of risk and lowest membership grade $(0.666)$, which reduces the risk level.

Number 8: Membership grade 0.007 is related to the sulfur granulation unit that obtained the highest level of risk and lowest membership grade (0.666), which reduces the risk level.

Number 9: Membership grade 0.0058 is related to the receiving and separating gas and gas condensate unit that obtained the highest level of risk and lowest membership grade (0.666), which reduces the level of risk.

Number 10: Membership grade 0.0119 is related to the condensate storage unit that obtained the highest level of risk and lowest membership grade $(0.666)$, which reduces the risk level.

Number 11: Membership grade 0.0061 is related to the gas system unit with high and low pressure towards the flare that obtained the highest level of risk and lowest membership grade (0.666), which reduces the level of risk.

Number 12: Membership grade 0.0073 is related to the gas sweetening unit that obtained 
Table 6. Ultimate criteria and sub-criteria weights affecting safe point zoning

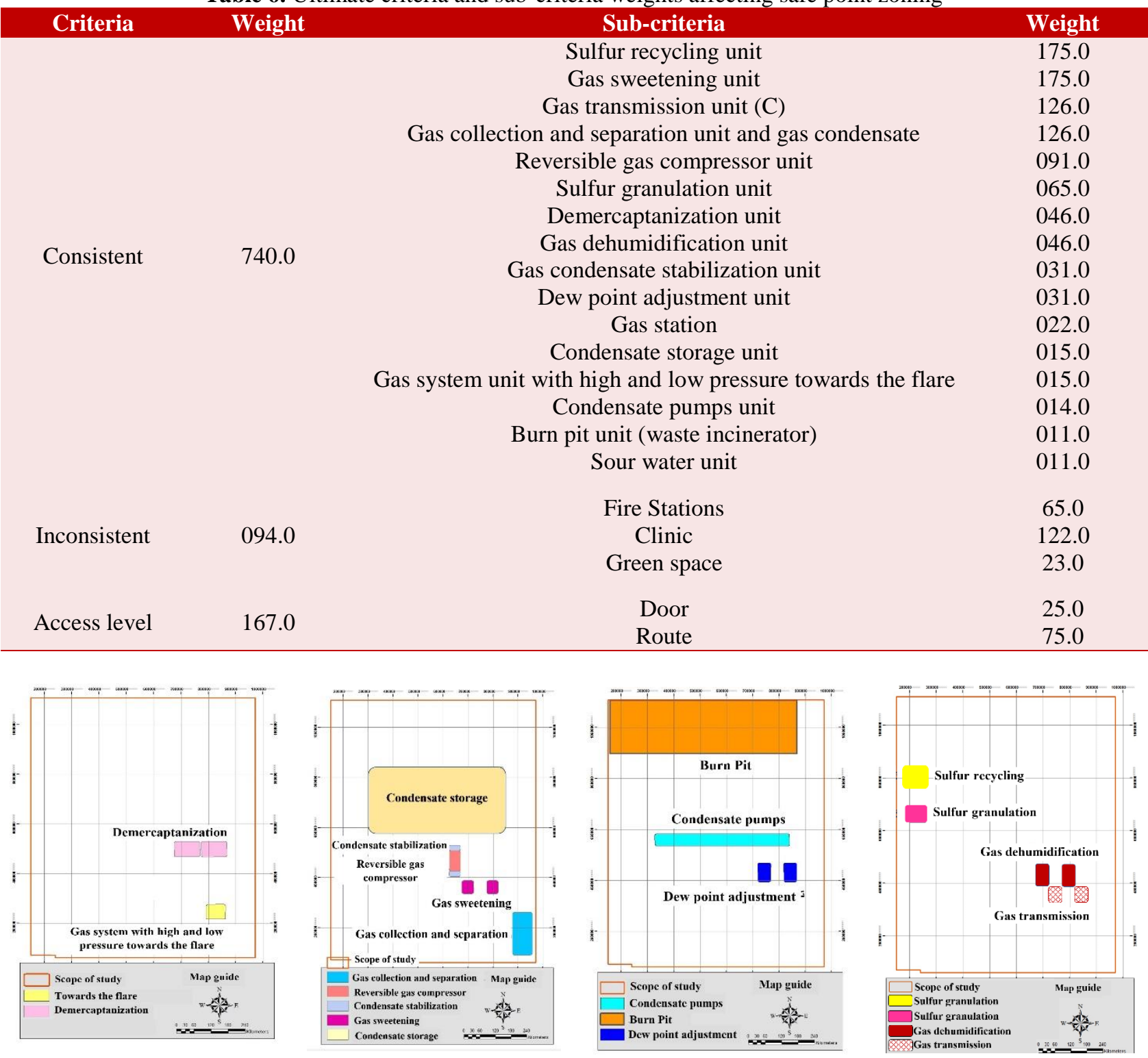

Figure 2. Location of units in the refinery

Table 7. Fuzzy layers of the factors affecting safe point zoning

\begin{tabular}{|c|c|c|c|}
\hline Criterion & Fuzzification & Criterion & Fuzzification \\
\hline Sulfur recycling $^{4}$ & Large & Condensate storage unit ${ }^{10}$ & large \\
\hline Gas sweetening $^{12}$ & Large & $\begin{array}{l}\text { Gas system unit with high and low } \\
\text { pressure towards the flare }\end{array}$ & large \\
\hline Gas delivery unit ${ }^{8}$ & Large & Condensate pump unit ${ }^{10}$ & large \\
\hline $\begin{array}{c}\text { Receiving and separation of gas and gas } \\
\text { condensate unit }\end{array}$ & Large & Burn pit unit (incinerator) ${ }^{5}$ & large \\
\hline Reversible gas compressor unit ${ }^{13}$ & Large & Sour water unit ${ }^{3}$ & large \\
\hline Sulfur granulation unit ${ }^{8}$ & Large & Fire station ${ }^{1}$ & small \\
\hline Demercaptanization unit 14 & Large & Clinic $^{1}$ & small \\
\hline Gas dehumidification unit ${ }^{15}$ & Large & Green space $^{1}$ & small \\
\hline Gas condensate stabilization unit ${ }^{6}$ & Large & Exit door ${ }^{1}$ & small \\
\hline Dew point adjustment unit ${ }^{7}$ & Large & $\begin{array}{l}\text { Exit route }{ }^{1} \\
\text { Gas station }^{2}\end{array}$ & $\begin{array}{l}\text { small } \\
\text { large }\end{array}$ \\
\hline
\end{tabular}


the highest level of risk and lowest membership grade (0.667), which reduces the level of risk.

Number 13: Membership grade 0.0085 is related to the reversible gas compressor unit that obtained the highest risk and lowest membership grade (0.667), which reduces the risk level.

Number 14: Membership grade 0.008 is related to the demercaptanization unit that obtained the highest level of risk and lowest membership grade (0.666), which reduces the level of risk.

Number 15: Membership grade 0.0078 is related to the gas dehumidification unit that obtained the highest level of risk and lowest membership grade (0.667), which reduces the level of risk.

Figure 4 shows the value of different units of the first refinery of the South Pars Gas Complex using AND, OR, Product, and Sum logic.

According to the fuzzy distance diagram, value 1 signifies different units of the refinery that obtained the highest level of risk. On the other hand, the lowest value (9) reduces the level of risk.

Therefore, green areas are less risky and can be regarded as safe assembly zones.

Figure 4 illustrates the value of different refinery units with gamma logics of 0.1-0.9. Moreover, the fuzzy distance diagram indicates that 1 is related to different units of the refinery that obtained the highest level of risk. On the other hand, the lowest score (9) signifies a reduced level of risk. As shown in this figure, very high sensitivity in zoning can be found in gamma 0.1, which is close to the fuzzy algebraic product operator results. On the other hand, very low sensitivity is observed in gamma 0.9 , which is close to the fuzzy algebraic sum operator. The points with inconsistencies and high priority to determine the safe places for assembly are revealed in gamma 0.9. Therefore, gamma 0.6 in this study shows the most appropriate safe assembly points during an emergency (regarding inconsistent factors) in the vicinity of the fire station, clinic, and water treatment plant.

\section{Discussion and Conclusion}

This study evaluated the reaction to emergencies, such as material release, as well as fire and explosion of toxic, flammable, and explosive chemicals in a refinery. In addition, the probable repeatability of the catastrophic scenarios was determined using the opinion of experts, previous studies, and databases of process equipment failure rate regarding the current situation in Iran. It is worth mentioning that the emergency response planning was implemented on fuzzy logic. This study utilized 5 fuzzy operators in the GIS environment, including fuzzy AND operator, fuzzy OR operator, fuzzy algebraic product operator, fuzzy algebraic sum operator, and fuzzy gamma operator, as well as their functions (gamma range:0.1-0.9) on 10 maps to analyze the results.

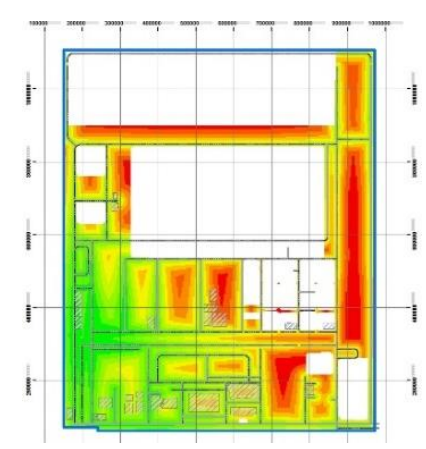

D

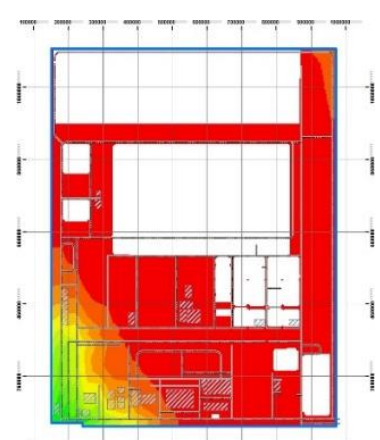

$\mathrm{C}$

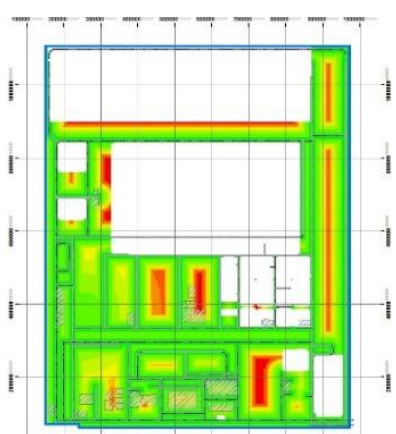

B

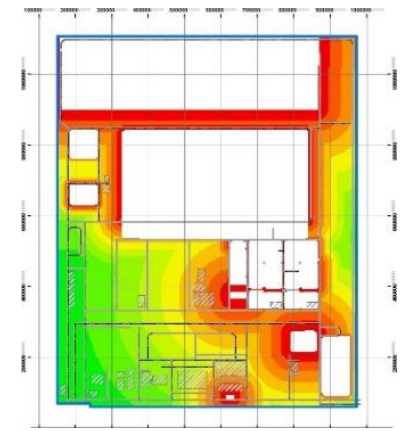

A

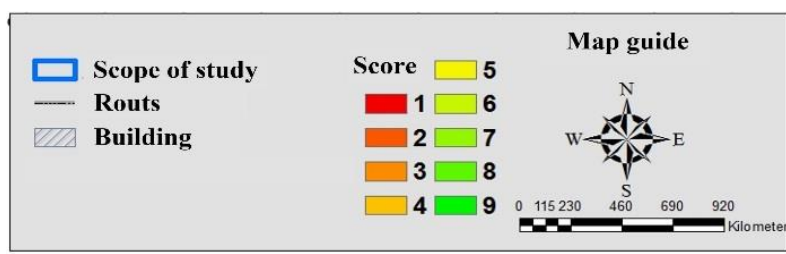

Figure 3. Fuzzy map of the first refinery of the South Pars Gas complex . A) AND logic, b) OR logic, c) Product logic, and d) Sum logic 
The results of OR and AND operators showed that inconsistent criteria were regarded in high priority; therefore, the identified zones did not have the required accuracy. According to a study conducted by Lee on the fuzzy algebraic product operators in mapping landslide-prone areas, it was shown that the accuracy of fuzzy AND operator, fuzzy OR operator was lower than that of other operators (23), which is consistent with the results of the present study. Accordingly, these two
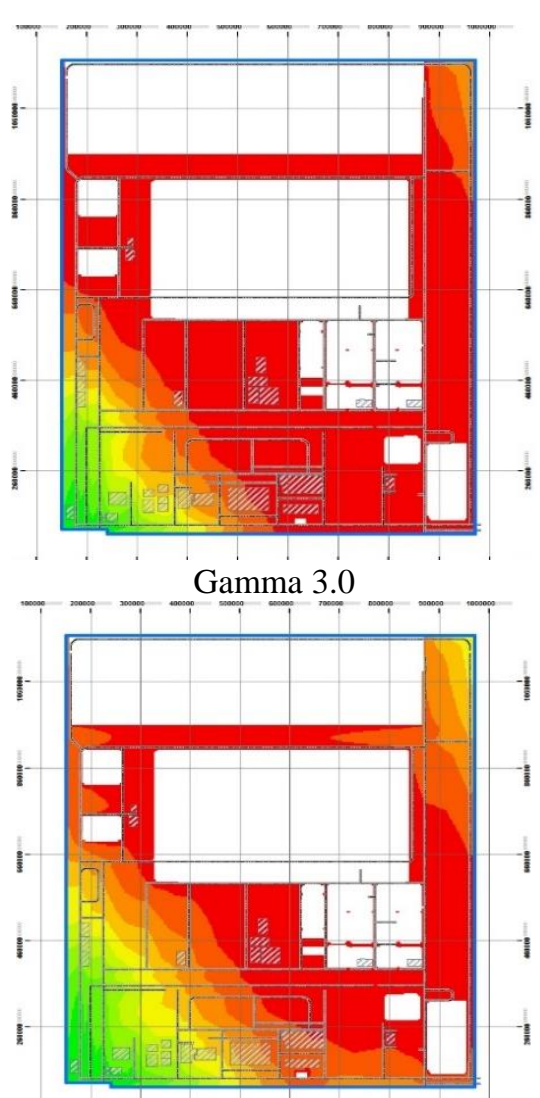

Gamma 6.0

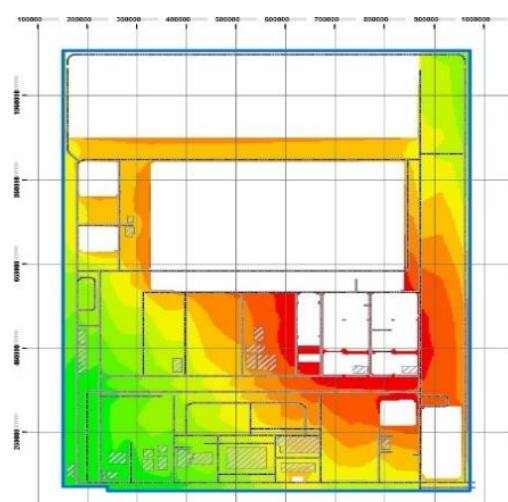

Gamma 9.0

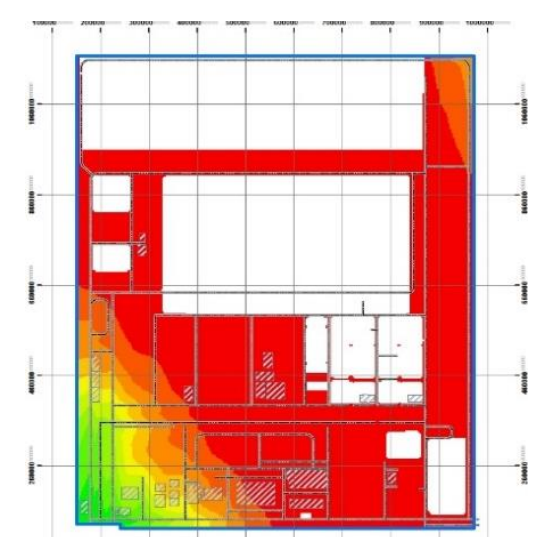

Gamma 2.0

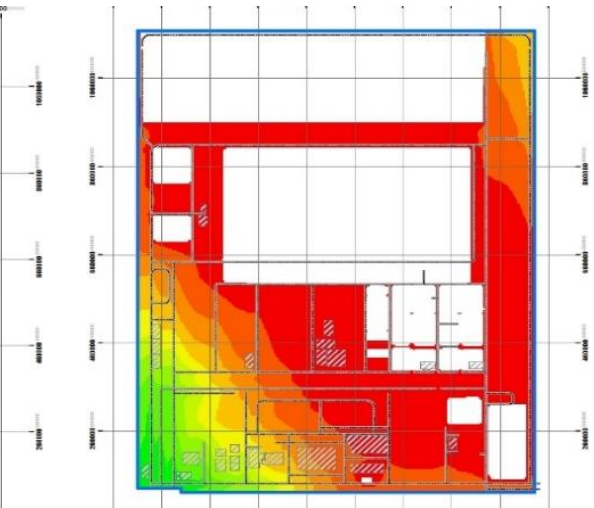

Gamma 5.0

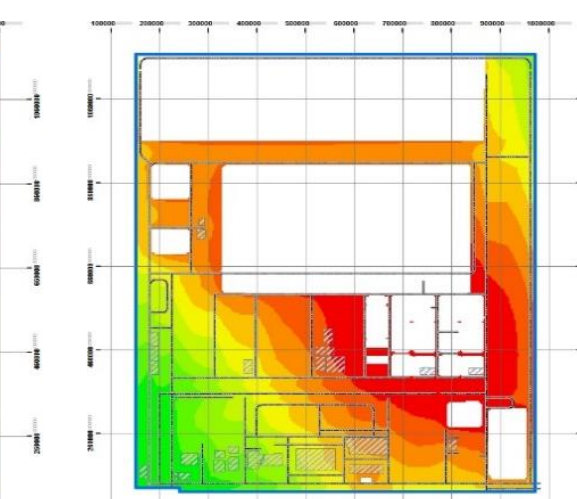

Gamma 8.0

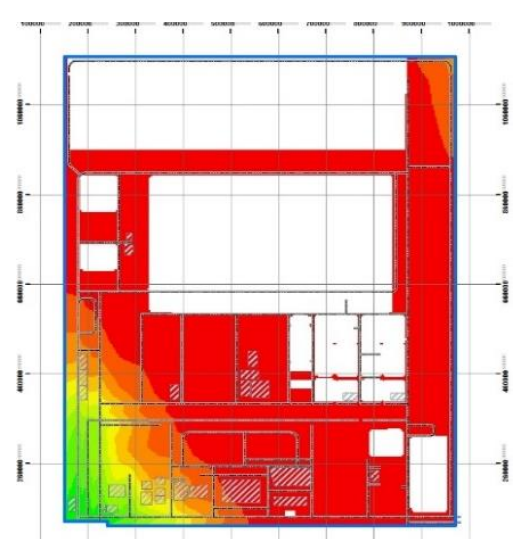

Gamma1.0

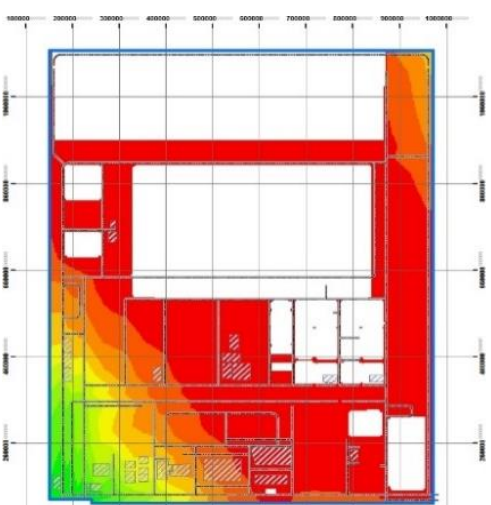

Gamma 4.0

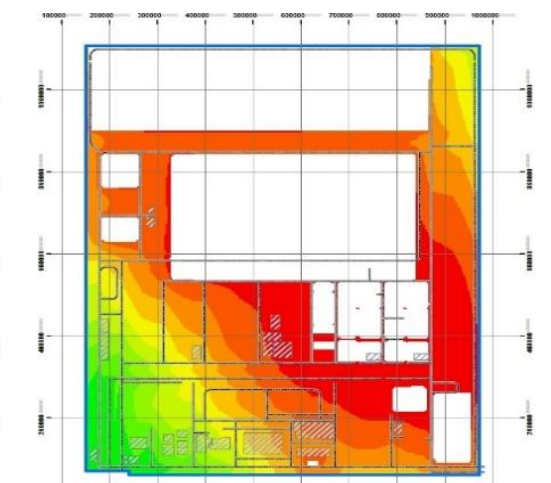

Gamma 7.0

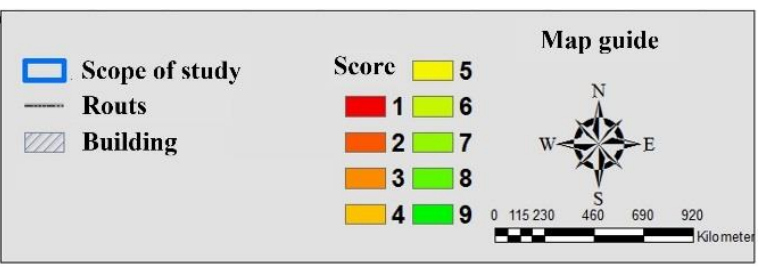

Figure 4. Fuzzy map with gamma logic 0.1 to 0.9 
operators identified many safe assembly areas, which show the low sensitivity of this method in determining the locations. This is because the fuzzy AND operator is the community operator of the sets that extracts the maximum degree of the membership. In other words, it extracts the maximum value (weight) of each pixel out of all information layers and considers it in the final map $(24,25)$. The output of the fuzzy algebraic sum operator shows the potential assembly areas including the non-industrial site (clinic, entrance door, office building). On the other hand, according to the obtained results, the inappropriate assembly areas were other industrial sectors, such as fire station; however, a part of the industrial site was safe with a medium to appropriate priority.

This may be due to the fact that in this operator, the complement multiplication is the complement; therefore, in the output map, unlike the fuzzy algebraic product operator, the value of the pixels tends to 1 . As a result, more pixels are considered within a very good class $(16,26-28)$.

The results of this study showed more sensitivity of fuzzy algebraic product operator in terms of zoning, compared to the fuzzy algebraic sum operator. However, the fuzzy algebraic operator (Product) multiplies the information layers and minimizes the output map numbers (tend to 0 ); therefore, it considers fewer numbers of pixels in a very good class. For this reason, this operator has high accuracy and sensitivity in zoning $(3,10)$. Accordingly, the results of this operator in the present study cannot represent all the safe places in this area.

This study identified the safe assembly areas using gamma 0.1-0.9. Therefore, the very high and low sensitivities are observed in gammas of 0.1 and 0.9 that are close to the results of the fuzzy algebraic product operator and fuzzy algebraic sum operators, respectively. All maps obtained from the fuzzy gamma emphasize on a few specific points. However, as we move towards 1 , the sensitivity to identify assembly areas decreases and shows wider areas to coordinate. Moreover, there is a decrease in the percentage of its overlap with zoning criteria, and in gamma 0.9 , the inconsistent areas obtained a high level of priority for assembly.

In this study, the accuracy of the zoning decreases with a gamma increase in the fuzzy logic model. As can be seen in the maps, the zoning accuracy and the percentage of overlap with the control areas are greatly reduced considering gamma 0.6 and above. Therefore, the results extracted from gamma 0.6 show 3 safe places within the area under study, including the region in the vicinity of the fire station, clinic, and wastewater treatment plant where employees should gather in the event of emergencies.

Regarding the identification of the safe assembly areas for employees in high-risk industries, such as the gas industry, the most important issue is to select the appropriate criteria for zoning. Moreover, it is of utmost significance to accurately determine the importance of variables. In this study, inconsistent variables were more remarkable in zoning in such industries, compared to consistent criteria.

According to the results, the fuzzy logic model has a high accuracy in zoning, which provides better results by eliminating uncertainties.

\section{Acknowledgments}

The authors express their gratitude to the officials in South Pars Gas Complex, the Pars Energy Special Economic Zone, and all those who contributed to conducting this study.

\section{Conflict of Interests}

$? ? ?$

\section{References}

1. Chang NB, Wei YL, Tseng CC, Kao CY. The design of a GIS-based decision support system for chemical emergency preparedness and response in an urban environment. Comp Environ Urban Syst 1997; 21(1): 67-94.

2. Dadashpour H, Khodabakhsh H. Optimal locations of temporary housing sites using a fuzzy analytic hierarchy process (FAHP), the case study of region 16 of Tehran. J Geography Plan 2012; 17(46): $67-$ 90. [In Persian].

3. Dou Z, Zhang Y, Zhang M, Jiang J, Chen Y. Emergency response capacity assessment of a chemical industrial park based on AHP-Fuzzy method. J Saf Environ 2015; 15: 29-34.

4. Hosseinnia B, Khakzad N, Reniers G. An emergency response decision matrix against terrorist attacks with improvised device in chemical clusters. Saf Secur Stud 2018; 1: 187-99.

5. King AA, Lenox MJ. Industry self-regulation without sanctions: the chemical industry's responsible care program. Acad Manag J 2000; 43(4): 698-716.

6. Ma SM, Zhang SS, Chen Y, Song GB, Gao P. 
Evaluating emergency response capacity of chemical industrial park using an hybrid fuzzy ahp method. J Harbin Instit Technol 2014; 2: 8.

7. Kholil M, Octaviani R. Application of AHP Method for selecting the best strategy to reduce environmental demage caused by non metallic mining case study in Gunungkidul Regency, Yogakarta, Indonesia. J Environ Eng Sci Technol Res 2013; 1(7): 98-109.

8. Hanine M, Boutkhoum O, Tikniouine A, Agouti T. An application of OLAP/GIS-Fuzzy AHP-TOPSIS methodology for decision making: location selection for landfill of industrial wastes as a case study. KSCE J Civil Eng 2017; 21(6): 2074-84.

9. Kristensen AS, Ahsan D, Mehmood S, Ahmed S. Unmanned aerial system for fast response to medical emergencies due to traffic accidents. World Acad Sci Eng Technol Int J Health Med Eng 2017; 5(11): 17.

10. Roshanaei V, Vahdani B, Mousavi SM, Mousakhani M, Zhang G. CAD/CAM system selection: a multi-component hybrid fuzzy MCDM model. Arabian J Sci Eng 2013; 38(9): 2579-94.

11. Li X, Zhao Z, Zhu X, Wyatt T. Covering models and optimization techniques for emergency response facility location and planning: a review. Mathem Methods Oper Res 2011; 74(3): 281-310.

12. Zhang JH, Li J, Liu ZP. Multiple-resource and multiple-depot emergency response problem considering secondary disasters. Exp Syst Appl 2012; 39(12): 11066-71.

13. Zhou J, Reniers G. Petri-net based evaluation of emergency response actions for preventing domino effects triggered by fire. J Loss Prev Proc Indust 2018; 51: 94-101.

14. Edelstein MR. When recreancy becomes the norm: emergency response planning and the case of tar sands upgrading in the alberta industrial heartland. In: Freudenburg WR, editor. A life in social research. Bingley: Emerald Group Publishing Limited; 2013.

15. Nieuwoudt C, Quinn LP, Pieters R, Jordaan I, Visser M, Kylin H, et al. Dioxin-like chemicals in soil and sediment from residential and industrial areas in central South Africa. Chemosphere 2009; 76(6): 774-83.

16. Ju Y, Wang A, Liu X. Evaluating emergency response capacity by fuzzy AHP and 2-tuple fuzzy linguistic approach. Exp Syst Appl 2012; 39(8):
6972-81.

17. Abdolhamidzadeh B, Rahimi F, Gharebaghian T, Nosraty B, Rashtchian D. Evaluating the functionality of industrial emergency operations center (EOC) by weighted scoring technique. Advances in fire and process safety. Singapore: Springer; 2018. P. 73-90.

18. Arru M, Negre E, Rosenthal-Sabroux C. Population behaviors in crisis situations-a study of behavioral factors in the PPI ineos emergency response exercise. Proceedings of the 51st Hawaii International Conference on System Sciences, Waikoloa Village; 2018.

19. Rikalovic A, Cosic I, Lazarevic D. The role of GIS in industrial location analysis. CIP 2014; 5: 299.

20. Amellal I, Bouzidi A. Industrial location-use of a tool for multi-criteria decision and GIS: An application to the Chaouia-Ouardigha region in Morocco. Int J Innovat Appl Stud 2016; 14(1): 243.

21. Hadipour M, Kishani M. Environmental location planning of industrial zones using Ahp and Gis In Arak City, Iran. Proc MISG 2014; 1: 109-14.

22. Zangiabadi A, Kiumarsi H. Spatial analysis and site selection post centers using Geographical Information System (Case study: zone $5 \& 6$ of Isfahan city). Geography Environ Plan 2012; 47(3): 19-22.

23. Lee S. Application and verification of fuzzy algebraic operators to landslide susceptibility mapping. Environ Geol 2007; 52(4): 615-23.

24. Ahn J, Chang D. Fuzzy-based HAZOP study for process industry. J Hazard Mater 2016; 317: 303-11.

25. Javidi M, Abdolhamidzadeh B, Reniers G, Rashtchian D. A multivariable model for estimation of vapor cloud explosion occurrence possibility based on a Fuzzy logic approach for flammable materials. J Loss Prev Proc Indust 2015; 33: 140-50.

26. Huang LJ. An FAHP-based quantitative method for risk assessment of debris-flow hazards using different fuzzy numbers. Int $\mathbf{J}$ Erosion Control Eng 2016; 9(2): 32-42.

27. Shi L, Shuai J, Xu K. Fuzzy fault tree assessment based on improved AHP for fire and explosion accidents for steel oil storage tanks. J Hazard Mater 2014; 278: 529-38.

28. Markowski AS, Siuta D. Fuzzy logic approach to calculation of thermal hazard distances in process industries. Proc Saf Environ Protect 2014; 92(4): 338-45. 